Rev. Biol. Neotrop. 3(1): 1-3. 2006

\title{
Na especie nueva del genero Staelia (Spermacoceae-Rubiaceae)
} PARA LA FLORA DE BRASIL

\section{Roberto M. Salas \\ Elsa L. Cabral}

Instituto de Botánica del Nordeste, UNNE-CONICET, C.C. 209, 3400, Corrientes, Argentina; Facultad de Ciencias Exactas y Naturales y Agrimensura, UNNE, Corrientes, Argentina, e-mail: ecabral@agr.unne.edu.ar; ferber@arnet.com.ar; robertoymanuels@ hotmail; robertoymanuels@gmail.com

Resumo: Uma espécie nova do gênero Staelia Cham. \& Schltdl. para a flora do Brasil é descrita e ilustrada. Se apresenta uma clave analítica para diferenciar as espécies afins.

Palabras-clave: Brazil, Rubiaceae, Spermacoceae, Staelia.

Aвstract: A new species of the genus Staelia Cham. \& Schltdl. from Brazil is described and illustrated. Staelia tocantinsiana Salas, R. M. \& E. L. Cabral. A key to differentiate the related species is provided.

KeY worDs: Brazil, Rubiaceae, Spermacoceae, Staelia.

\section{INTRODUCCIÓN}

$S_{\text {taelia } \text { Cham. \& Schltdl., es un género }}$ sudamericano, tiene alrededor de 14 especies (Andersson, 1992; Souza \& Sales, 2004; Cabral \& Salas, 2005) la mayor parte de las cuales habitan el centro-este de Brasil. Schumann (1889) en Flora Brasiliensis reconoce para el género 10 especies, a las que Kirkbride (1997) agrega una nueva especie del Estado de Minas Gerais. En este trabajo se propone $S$. tocantinsiana Salas, R. M. \& E. L, Cabral como especie nueva, la misma se describe e ilustra a continuación.

\section{Resultados y Discusión}

Staelia tocantinsiana Salas \& E. L. Cabral sp. nov. (Fig. 1).

Suffrutex $50-70 \mathrm{~cm}$ altis, foliis $10-20 \mathrm{~mm}$ longis, glomeruli floralis 3-5 in ramis floriferis, corolla 5,5-6 mm longa, stilo bifidus, ramis 3$3,6 \mathrm{~mm}$ longis, disco integro, capsula valvis supernes hirtis, calicys segmentis glabris 1,3$1,5 \mathrm{~mm}$ longis.

Tipo: BRASIL. Tocantins: Ilha do Bananal, Parque Nacional do Araguaia. Mun.
Lagoa da Confusão, Praia do Grado, campo sujo graminoso, relevo plano, $180 \mathrm{~m}, 10^{\circ} 24^{\prime} 02^{\prime \prime} \mathrm{S}$, 50²9'07"W, 23.III.1999 (fl, fr), M. A. da Silva et al. 4091 (holotipo, IBGE n.v., isotipo, CTES). (Fig. 1).

Sufrútice $50-70 \mathrm{~cm}$ alt., de tallos cilíndricos a subcilíndricos, fistulosos, glabros a glabriúsculos, con entrenudos de $15-45 \mathrm{~mm}$ long. Hojas opuestas, seudoverticiladas, de 10-20 x 0,5-1 mm, lineares a linear-lanceoladas, apiculadas, glabras. Vaina estipular 1-1,4 mm long, glabra o glabrescente, con 3 lacinas de 0,3-1 mm long. Glomérulos 3-4 (-5) por rama florífera, de (8-) 10-15 mm lat., brácteas involucrales 2 . Hipanto 0,6-0,8 mm long., turbinado híspido en la mitad superior; segmentos del cáliz linear-subulados, erguidos, pestañosos, 1,3-1,5 mm long.; Corola 5,5-6 mm long., glabra y solo con anillo de pelos moniliformes \pm en la mitad interna del tubo corolino. Estambres 1,82,2 mm long., igual a los lobulos de la corola, anteras 0,7-0,8 mm long. Estilo 5-6,5 mm long, bífido, ramas del estilo 3-3,6 mm long. Disco entero. Cápsula con las valvas híspidas en la 


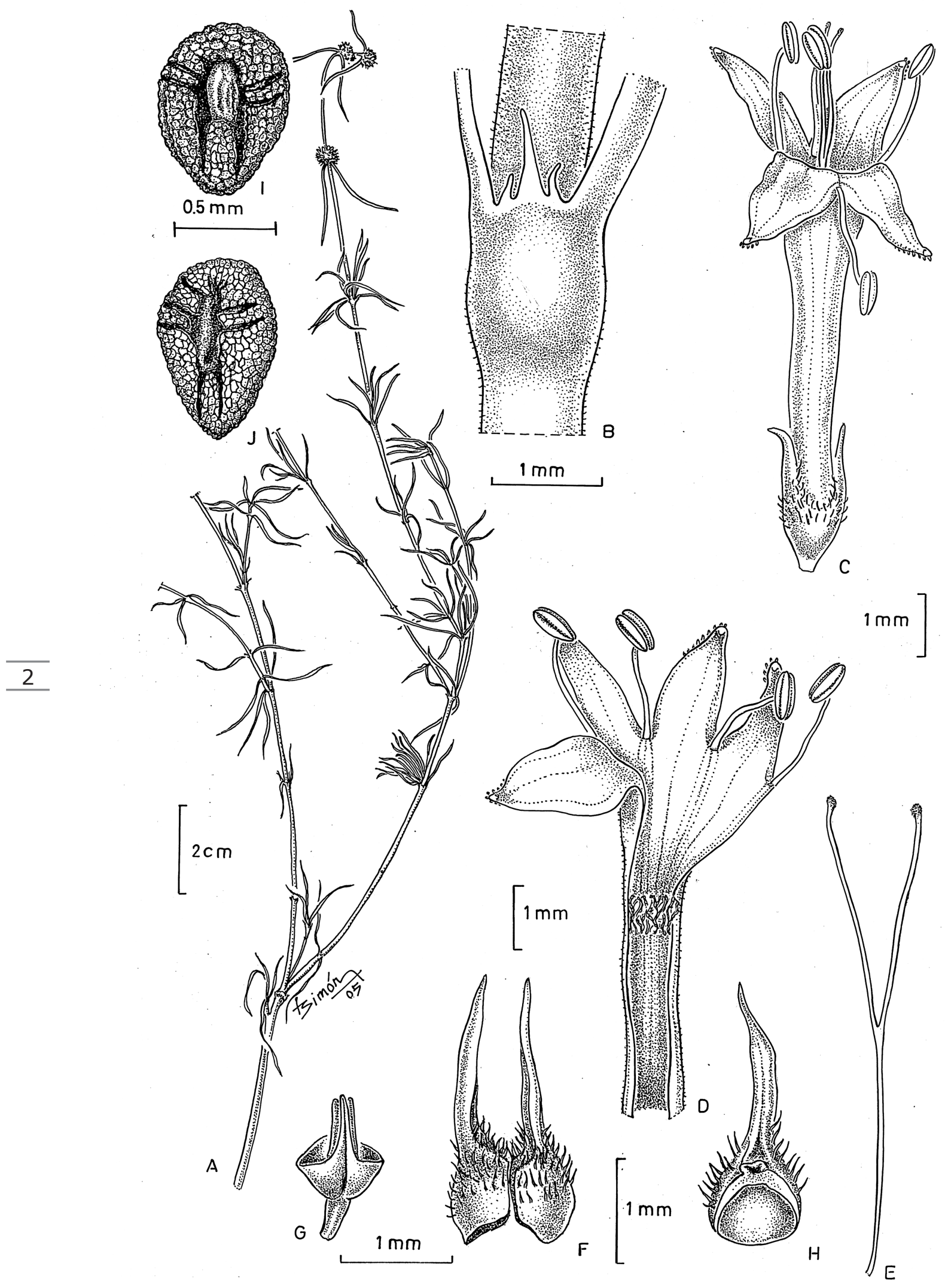

Figura 1 - Staelia tocantinsiana Salas \& E. L. Cabral. A. Porte. B. Vaina estipular. C. Flor. D. Corola abierta. E. Estilo. F-H. Fruto. F. valvas caducas, vista lateral. G. Base persistente. H. valva caduca, vista interna. I. Semilla, vista ventral. J. Semilla, vista parcial-lateral. (de M. A. da Silva et al. 4091). 
mitad superior, base glabra. Semilla subelipsoide, 0,8-1 mm long., reticulado-faveolada, surco rodeando el estrofíolo con 2-3 canales estrechos tranversales que se prolongan parcialmente sobre el borde.

Distribución y Ecología. Hasta el presente solo se halló en el estado de Tocantins. Planta heliofita, en pequeñas matas. Abundante localmente. Debido a que solo se contó con el ejemplar tipo no se pudo establecer la fenología, en él se encuentran flores y frutos en Marzo.

La relación de Staelia tocantinsiana con las especies más afines está representada en la siguiente clave $[S$. aurea $\mathrm{K}$. Schum.y $S$. virgata (Wild. ex Roem. \& Schult.) K. Scum. var. virgata].

\section{Clave para diferenciar las espécies afines}

1. Glomérulos 3-4 (-5) por rama florífera. Estilo bifido, ramas estilares 3-3,6 mm long. Semilla, cara ventral con 2-3 canales estrechos tranversales que se prolongan parcialmente sobre el borde. Vaina estipular con tres lacinias glabra o glabrescente. Segmentos del cáliz de 1,3-1,5 $\mathrm{mm}$ long. Entrenudos con rala pubescencia cerca de los nudos foliares

Staelia tocantinsiana

1. Glomérulos 6-30 por rama florífera. Estilo entero. Semilla, cara ventral sin canales tranversales, a veces con cortos surcos que no llegan al borde. Vaina estipular con (-3) 5-7 lacinias, pubérula a pubescente. Segmentos del cáliz de (1,5-) 2-2,5 mm long. Entrenudos pubérulos, pubescentes, glabrescentes o glabros.

2. Entrenudos apicales floríferos glabros o glabrescentes, cuadrangulares. Semillas con surco ventral prolongado hasta el polo inferior. Staelia aurea

2. Entrenudos apicales floríferos pubérulos a pubescentes, cilíndricos a subcilíndricos. Semillas con surco ventral en el polo inferior con dos cortas prolongaciones que no llegan al borde. Staelia virgata var. virgata

\section{Agradecimientos}

Agradecemos a la Prof. Nélida Bacigalupo por la corrección del manuscrito y a la dibujante Laura Simon por su aporte en la ilustración.

\section{Referencias}

Andersson, L. 1992. [Staelia] A provisional checklist of Neotropical Rubiaceae. Scripta Bot. Belg. 1: 195.

Cabral, E. L. \& R. M. Salas. 2005. Novedades en el género Staelia (Rubiaceae) para Argentina. Bonplandia 14 (1-2): 83-89.

Kirkbride, J. H. 1997. [Staelia] Manipulus rubiacearum VI. Brittonia 49: 376-378.

Schumann, K. 1889. [Staelia] Rubiaceae. In: C. P. F. Martius et al. (Eds.), Fl. Bras. 6 (6): 71-76. Fleisher, Leipzig.

Souza, E. B. de \& M. Ferreira de Sales. 2004. O gênero Staelia Cham. \& Schltdl. (Rubiaceae-Spermacoceae) no Estado de Pernambuco, Brasil. Acta Bot. Bras. 18 (4): 919-926.

Recebido 15.V.2006

Aceptado 05.IX.2006 